\title{
Design and Implementation of Matrix Converter with Unipolar IGBT
}

\author{
Yanzhe $\mathrm{Li}^{1, \mathrm{a}}$, Jiajia Jing ${ }^{2, \mathrm{~b}}$, Qirong $\mathrm{Wu}^{3, \mathrm{c}}$ and Wenxia Zhang ${ }^{4, \mathrm{~d}}$ \\ School of Automation \& Electrical Engineering, Lanzhou Jiao Tong University, China \\ aemail:yanzhe866@mail,Izjtu.cn, ${ }_{\text {demail:1508186294@qq.com, }}^{\text {eemail:2668148079@qq.com }}$ email:1259325519@qq.com,
}

Keywords: Matrix Converter; Three-phase to Single-phase; Unipolar IGBT; Sector Judgment Abstract: The paper proposes a matrix converter using unipolar IGBT, which is composed of three-phase rectifier and single-phase inverter, and transforms three-phase AC into single-phase AC. The main characteristic of converter lies on the only use of the unidirectional power transistor and no need DC support capacitor. The three-phase rectifier adopts the synchronous rectification control strategy based on sector judgment to obtain six pulse DC bus voltage and export single-phase AC power that can be adjusted in terms of frequency and amplitude by the single inverter. A $1.75 \mathrm{kVA}$ prototype has been designed and made out. The simulation results and prototype experiment are the same which verify the feasibility of the proposed converter.

\section{Introduction}

The indirect three-phase to single-phase converter has been widely used in industrial control fields. Fig. 1 shows the topology of indirect converter. In this structure, three-phase AC (alternating current) power supply voltage is rectified in the front stage, and the output is filtered and regulated by the DC (Direct-current) supporting capacitor. Thus, a stable DC bus voltage is gained. Using the latter stage inverter, single phase alternating current is obtained. In this converter, the DC supporting capacitor with huge volume will resulting in the cost increases of the converter, and make the presence of current overshoot during start-up in the converter.

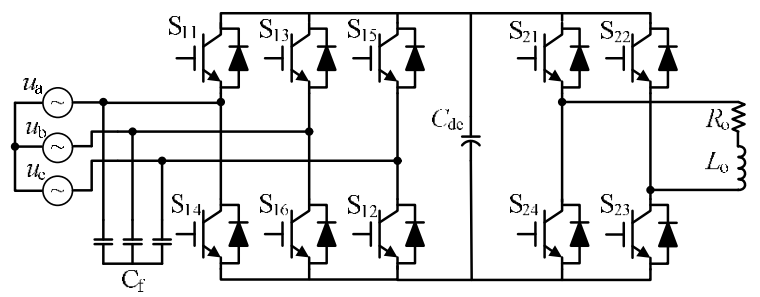

Fig.1. The traditional three-phase to single-phase converter

Matrix converter is a direct converter that changes three phases AC to single phase AC. Fig.2 shows the topology of traditional matrix converter. Matrix converter achieves AC/AC conversion without intermediate supporting capacitor, and has gained widespread attention ${ }^{[1-4]}$. However, the outstanding issues of matrix converter are the complexity of the control and a huge number of switches.

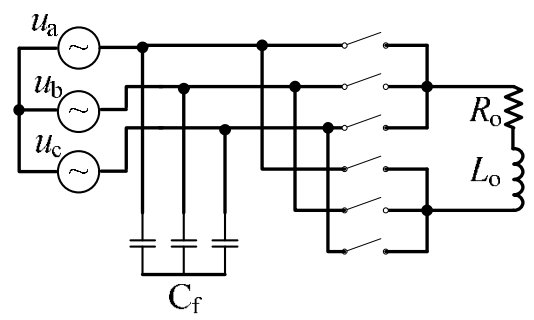

Fig.2. The traditional three-phase to single-phase matrix converter

This paper proposes a three-phase to single-phase matrix converter by using unipolar IGBT (Insulated Gate Bipolar Transistor) instead of IGBT consisting of two two-way switches in the traditional matrix converter. Meanwhile, by adopting the synchronous rectification control strategy 
based on judgment of the sector, the converter can get DC bus voltage of six -pulse without the DC supporting capacitor, which solves the problems caused by bulky capacitor and current overshoot during start-up in traditional indirect converter.

\section{Topology and Working Principle}

Fig. 3 shows the matrix converter structure using unipolar IGBT, which consists of three-phase input capacitor, three-phase rectifier, half-bridge inverter, resistive load $\mathrm{R}_{0}$ and inductive load $\mathrm{L}_{0}$. By three-phase synchronous rectification, the rectifier transforms the three-phase AC voltage into six-pulse DC bus voltage. Then, the single-phase AC power is gained through the inverter. Every switch of the converter is a unipolar IGBT, which is different from the traditional matrix converter composed of at least two IGBT.

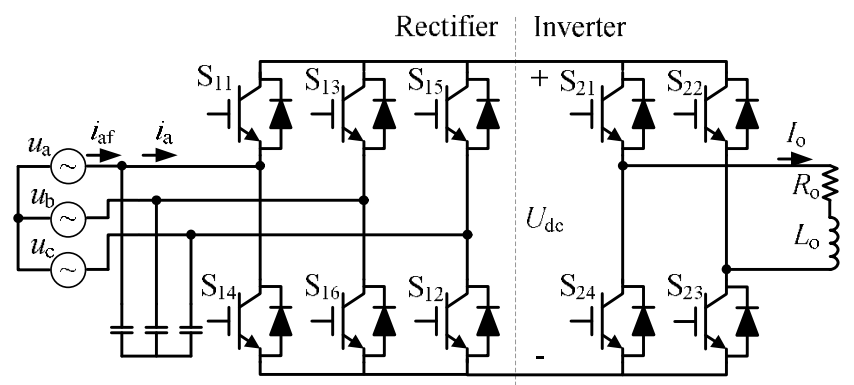

Fig.3. Three-phase to single-phase matrix converter using unipolar IGBT

In the Fig.3, the switch frequency on rectifier side is consistent with the frequency of input voltage. Rectifier adopts the synchronous rectification control strategy based on the judgment of sectors and the switches work at the state of synchronous rectification, so the switching loss of rectifier switch is almost zero. SPWM (Sinusoidal Pulse Width Modulation) is used on inverter side, and the switch frequency is several kilohertz. Changing the frequency (or magnitude) of fundamental modulation signal can realize the regulation of the frequency (or magnitude) for output voltage.

The converter does not need DC supporting capacitor, so there is no current overshoot during start-up in the converter, which is unable to realize in conventional three-phase to single-phase indirect converter. Since the inverter and rectifier are controlled independently, we can turn off the driving of inverter and can keep rectifier working during energy feedback. The energy stored in the inductance load can be fed back to the input side directly, and does not cause any voltage overshoot. This matrix converter is superior to conventional matrix converter in energy feedback.

\section{Control Strategy}

In inverter side of converter, SPWM (Sinusoidal Pulse Width Modulation) is used. In rectifier side of converter, in order to make the switch work at the maximum phase and minimum phase of the three-phase input voltage, and output DC bus voltage with six-pulse wave, the driving signal of IGBT needs to be modulated on the base of input voltage. The three phase AC input signal is divided into six sectors according to rectifier modulation strategy. Switching logic is illustrated in Fig.4. Fig.4 shows that conduction time of each switch occupies two adjacent sectors, and there are and only two switches keeping conduction when sector is switched.

The key to adopt this modulation strategy lies in determining accurately the switching point of sector. If the sector is switched in advance, and the voltage difference between the two switches(such as S11 and S12) is non-zero, the switching process will causes current overshoot and result in waveform distortion. If the sector switching is delayed, the switch (such as S11) before switching and anti-parallel diode of the switch (such as S12) after switching are turned on together, resulting in waveform distortion. 


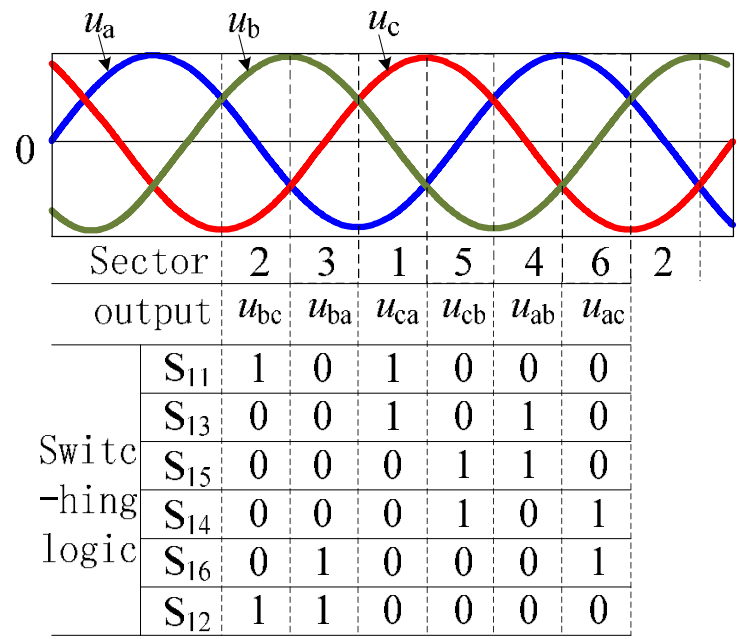

Fig.4. Sector division diagram and switching logic chart

\section{Design and Implementation}

In matrix converter, there is no isolation between the input side and output side, and the energy can be transmitted directly without storage and buffer of intermediate capacitor. Since the inverter operates at high frequency switching state, while taking into account the stray inductance and diode reverse recovery, the current in inverter input side contains a large number of high frequency components. So, the high frequency current will be directly injected into the input side of converter. If these high frequency components are not filtered, these high frequency components will lead to abnormal fever of the source power transformer in the input side of converter, even damage the transformer.

The following factors are considered during designing of the filter: cutoff frequency, damping coefficient, filter capacitor ripple and damping resistor losses. In order to reduce cost, we adopt LC (inductance capacitance) filter, and use the isolation transformer leakage inductance as filter inductance. Thus, we only need to design the filter capacitor and damping resistance. LC filter containing only inductance and capacitance is a second-order underdamping system and damping is almost zero. Under the influence of the harmonic currents of the output side, the filter inductance current and filter capacitor voltage will come into being resonance and damage device. Therefore, LC filter requires damping resistor in series with the inductance or capacitor. As shown in Fig.5, damping resistor $\mathrm{R}_{\mathrm{f}}$ is connected in series with the filter capacitor. The transfer function between network current $i_{\text {af }}$ in the source side and unfiltered current $i_{\mathrm{a}}$ is:

$$
G(s)=\frac{1+R_{\mathrm{f}} C_{\mathrm{f}} \cdot s}{L_{\mathrm{f}} C_{\mathrm{f}} \cdot s^{2}+R_{\mathrm{f}} C_{\mathrm{f}} \cdot s+1} \cdot
$$

Where the filter characteristic frequency $f_{\mathrm{n}}$ and damping $\zeta$ respectively is:

$$
\begin{gathered}
f_{\mathrm{n}}=\frac{1}{2 \pi \sqrt{L_{\mathrm{f}} \cdot C_{\mathrm{f}}}} . \\
\varsigma=\frac{R_{\mathrm{f}}}{2} \sqrt{\frac{C_{\mathrm{f}}}{L_{\mathrm{f}}}} .
\end{gathered}
$$

The transformer leakage inductance of input side is $L_{\mathrm{f}}=6.2 \mathrm{mH}$. Finally, we choose $f_{\mathrm{n}}=$ $f_{\text {sw }} / 5=600 \mathrm{~Hz}, \quad \zeta=0.3$. Substituting these parameters into Eq. 2, Eq. 3, $11 \mathrm{uF}$ capacitance and $14 \Omega$ resistance are available.

Prototype is built to verify the feasibility of the proposed converter, and prototype block diagram is shown in Fig.6. As shown in Fig.6, control chip is TMS320F2812, and double-loop control strategy is adopted in inverter side to obtain the stable output voltage and current. Firstly, two phase input voltage are sampled by Hall voltage sensor at input side, and a third phase voltage will be generated by software. According to the aforementioned control strategy, the sectors are determined and 
generate the switching signals. The output voltage and current are sampled by the Hall voltage and current sensors, then enter the DSP chip through signal conditioning circuit.

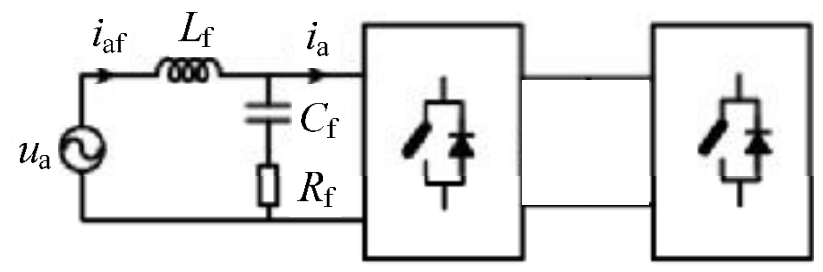

Fig.5. Single-phase equivalent circuit of filter

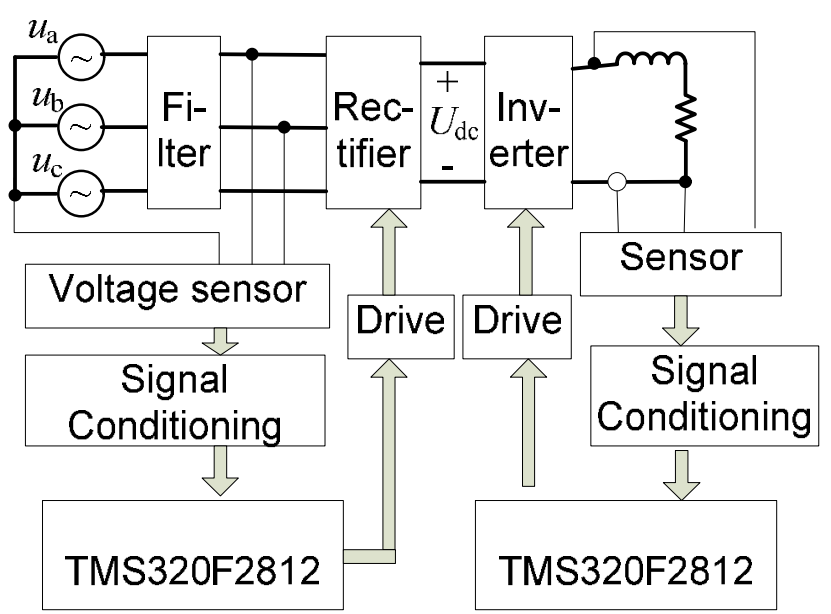

Fig.6. Prototype block diagram

\section{Simulation and Experiment Test}

A $1.75 \mathrm{kVA}$ prototype is designed. The input line voltage is $180 \mathrm{~V}$, input filter inductance is $6.2 \mathrm{mH}$, filter capacitor is $10 \mathrm{uF} / 630 \mathrm{~V}$, filter capacitor series resistance is $15 \Omega / 50 \mathrm{~W}$. Rectifier switch has been implemented in a 6MBP50VBA120-50 of Fuji Electric, so as the inverter switch, but only two switches are used. Load resistance is $18.5 \Omega / 5 \mathrm{~kW}$, load inductance is $50 \mathrm{mH}$, the switching frequency of the inverter is $3 \mathrm{kHz}$.

Simulation and experiment are carried out to demonstrate the feasibility of the converter. Fig. 7 shows the simulation and experimental results. Fig.7(a) shows the simulation and experiment compared waveform of six pulse $\mathrm{DC}$ voltage $\mathrm{U}_{\mathrm{dc}}$ and the input line voltage $\mathrm{u}_{\mathrm{ab}}$, from which we can find that the judgment of sector switching point is accurate, and simulation waveform is correspond with experimental waveform. Fig.7 (b) shows the simulation and experimental compared waveform of output current $\mathrm{I}_{\mathrm{o}}$. As shown in Fig.7 (b), the THD(Total Harmonic Distortion) of prototype experimental waveform is greater than simulation waveform, which is caused mainly by high frequency switching of switches in the inverter side. However, the sine characteristics of fundamental current that prototype produces isn't influenced.

\section{Conclusions}

This paper presented a novel three-phase to single-phase matrix converter, and analyzed the work principle of the converter, designed and completed a $1.75 \mathrm{kVA}$ prototype. The coincide of simulation and experimental results verify the feasibility of the proposed converter. The work of this paper enriches the optional matrix converter topology. 


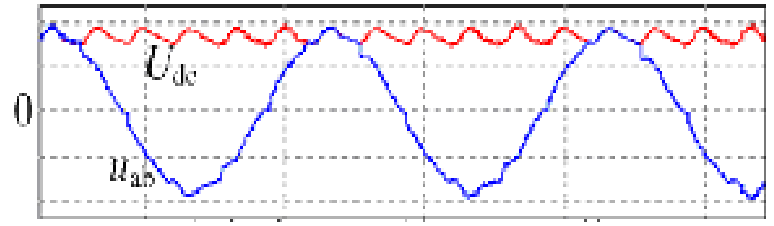

Simulation waveform (s)

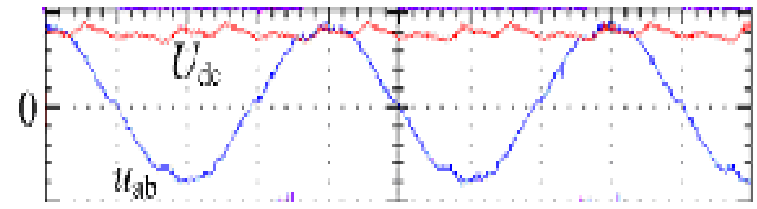

Experimental waveform (s)

(a)

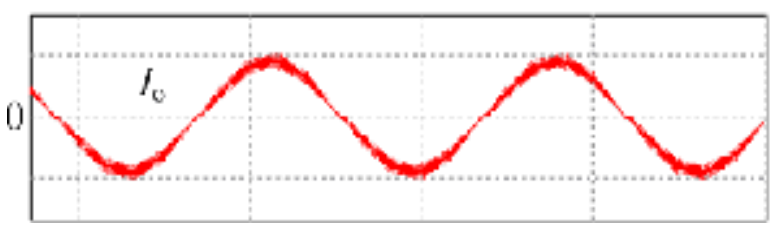

Simulation waveform（s）

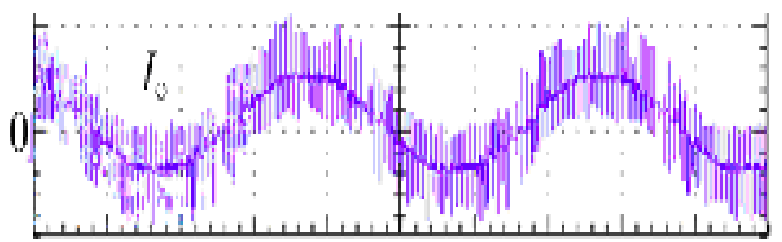

Experimental waveform (s)

(b)

Fig.7. Waveform of simulation and experiment

\section{Acknowledgements}

This work was financially supported by National merit-based personnel abroad visiting scholar funded projects (25200604).

\section{References}

[1] Zhou D,Sun K,Liu Z. A novel driving and protection circuit for reverse-blocking IGBT used in matrix converter[J]. IEEE Transactions on Industrial Electronics, 2007, 43(1): 3-13.

[2] ZHAO Kui-yin, YANG Qing, TANG Yong-qi. Novel Remedial Control Approach of Switching Function for Improving Reliability of AC-AC Matfix Converter[J]. Electric Drive, 2008, 38(11):34-36.

[3] Wen Feng, Jiang Jiu-chun, Guo Hui-ping. AC / DC Converter Based on Matrix Converter[J]. TRANSACTIONS OF CHINA ELECTROTECHNICAL SOCIETY, 2009, 24(3):128-131.

[4] GANG Yi, TIAN Lian-fang, WANG Xiao-hong, et al. Closed-loop control of permanent magnent synchronous motor based on dual space vector modulated matrix converter[J]. Electrical Measurement \& Instrumentation, 2010, 47(11):7-11. 